\title{
Patrimonio pedagógico del Siglo XX, UNA HERENCIA CULTURAL A PROTEGER: El Museu Pedagògic de Castelló (MPdC) Y SUS TAREAS DE CONSERVACIÓN Y RESTAURACIÓN
}

Twentieth century pedagogical heritage, protecting a cultural inheritance: The Castelló Education Museum and its conservation and restoration work

\author{
Elvira Safont Cruz \\ Conservadora y Restauradora de Bienes Culturales freelance \\ esafontc@gmail.com \\ https://orcid.org/0000-0001-5744-0996
}

\begin{abstract}
RESUMEN: En este artículo se dan a conocer los fondos del Museu Pedagògic de Castelló (MPdC) mediante la presentación de las labores en conservación y restauración que se realizan de los mismos. Se aborda desde el origen de este museo tal particular, así como las características de sus fondos, en qué estado de conservación se encuentran las piezas, y qué intervenciones son las más realizadas y su porqué. Los tratamientos generales de piezas como modelos anatómicos desmontables destinados a la enseñanza del cuerpo humano, mapas físicos y políticos escolares de papel, una serie de mapas negros pintados a mano que permiten ser escritos con tiza, modelos botánicos, modelos geográficos y maquetas de animales, son explicados para entender las labores de conservación en las que el museo se apoya para realizar una puesta en valor de todo su patrimonio. Finalmente, se hace una reflexión sobre las labores que realiza la entidad por y para sus fondos y los ciudadanos.
\end{abstract}

Palabras clave: Patrimonio pedagógico, conservación, restauración, museo pedagógico.

ABSTRACT: This article brings to light the collections of the Castello Education Museum (MPdC, its Spanish acronym) through its conservation and restoration work. It discusses the origins of this exceptional museum, the nature of its collections, the state of conservation of its pieces, and the most common 
interventions and the reasons behind them. The museum's conservation work is explained through its restoration of pieces such as anatomical models used to teach the human body, physical and political geography maps for schools, a set of black, hand-painted maps that can be written on with chalk, botanic models, geographic models and models of animals, all of which underpin the value of its heritage. The article ends with a reflection on the work the museum carries out by and for its collections and the community.

KeYWORDS: Pedagogical heritage, conservation, restoration, education museum.

RESUM: En aquest article es donen a conéixer els fons del Museu Pedagògic de Castelló (MPdC) mitjançant la presentació de les labors en conservació i restauració que es realitzen d`aquests. S'aborda des de l'origen d'aquest museu tal particular, així com les característiques dels seus fons, en quin estat de conservació es troben les peces, i quines intervencions són les més realitzades i el seu perquè. Els tractaments generals de peces com a models anatòmics desmuntables destinats a l'ensenyament del cos humà, mapes físics i polítics escolars de paper, una sèrie de mapes negres pintats a mà que permeten ser escrits amb guix, models botànics, models geogràfics i maquetes d'animals, són explicats per a entendre les labors de conservació en les quals el museu se secunda per a realitzar una posada en valor de tot el seu patrimoni. Finalment, es fa una reflexió sobre les labors que realitza l'entitat pels seus fons - i per als seus fons- $\mathrm{i}$ els ciutadans.

Paraules Clau: Patrimoni pedagògic, conservació, restauració, museu pedagògic. 


\section{Introducción}

$\mathrm{L}$

a mesa del colegio, los antiguos mapas físicos y políticos, las viejas

pizarras..., son objetos que forman parte de la identidad de nuestro sistema educativo. En su momento formaron parte de un obviado entorno académico, mientras que hoy en día son un valioso referente de cómo se vivió y erigió la escuela, y pertenecen al patrimonio cultural del siglo XX. En este artículo, se muestran los trabajos realizados en el Museo Pedagógico de Castellón (MPdC), destacando las intervenciones en conservación y restauración realizadas en sus fondos hasta el momento.

Los fondos antiguos de la colección se forman entre 1900 y 1960. Desde su inicio hasta 1992, el fondo es trasladado varias veces de edificio hasta que en 2002 se instala en la nueva Facultad de Ciencias Humanas y Sociales de la Universitat Jaume I, donde se encuentra hoy en día. La idea de construir un museo para los fondos nace de la celebración del primer centenario de los estudios de Magisterio en Castellón durante el curso 2000-2001, pero no será hasta el 2014 cuando comiencen las negociaciones para arrancar el museo como tal. Los cambios acaecidos en el equipo decanal de la Facultad de Ciencias Humanas y Sociales aceleran significativamente el avance de la negociación del museo por dos razones: la obtención de la primera financiación con fondos de la facultad y la entrada de colaboradores dentro de la organización, como la Fundación Soler i Godes y otras participaciones a nivel individual. La cesión del espacio de exposición en el edificio del Menador y las primeras exposiciones de los fondos durante el 2017 y el 2018, señalan el final del primer ciclo de la historia del Museo. Durante el 2019 se establece una nueva dinámica de trabajo con el proyecto que hoy en día está en vigor. El diseño actual del Museo Pedagógico de Castellón tiene como propósito continuar con los trabajos ya iniciados y avanzar hacia un proyecto heterogéneo que se constituya como impulsor de la innovación y el debate pedagógico en su territorio. Este proyecto no sería posible sin los diversos colectivos y profesionales de dentro y fuera de la universidad, habiéndose formado una comisión de trabajo para llevarlo a cabo. El MPdC pertenece, además, a la Red Mein-PHE de la Sociedad Española para el Estudio del Patrimonio Histórico-Educativo (SEPHE). 
Una de las labores del proyecto impulsor del museo es la conservación y restauración de las piezas. Estas labores se realizan bajo las directrices del código ético de la profesión del conservador: el conservador-restaurador respeta la importancia estética, histórica, espiritual y la integridad física del patrimonio cultural confiado a su cuidado, teniendo en cuenta los requisitos de su uso social a la vez que preserva el patrimonio cultural (ACRE, 2003).

Durante las intervenciones realizadas en los fondos del MPdC, se han tenido en cuenta las características principales de los objetos. Al tratarse de piezas que en su origen fueron confeccionadas para su uso académico y no para su exposición en un museo, su estado de conservación se corresponde con dicha vida útil. Por ello, la misión principal ha sido en todo momento intervenir tan solo las piezas que lo necesitaban y bajo la premisa de respetar su apariencia estética e histórica original.

\section{Características de los fondos intervenidos}

El Museo Pedagógico de Castellón presenta, dado su origen y su función, un fondo muy heterogéneo. Estos fondos abarcan desde material escolar del siglo pasado hasta objetos tecnológicos que, en su momento, consiguieron hacernos la vida más fácil pero que hoy en día su tarea ya finalizó y han quedado obsoletos. Ahora quedan abrigados bajo esta institución con el fin de ser un vestigio original de un pasado no muy lejano que abarca un sector un tanto desconocido dentro del patrimonio contemporáneo del siglo XX. La procedencia de dichos fondos proviene del Fondo Antigua Escuela de Magisterio de Castellón, Fondo Fundación Cátedra Enric Soler i Godes y fondos propios del MPdC. Este abarca equipos (de electricidad, de óptica, de física, de química, etc.), colecciones (fósiles, mapas, maquetas, modelos anatómicos, pinturas, etc.), herramientas de marquetería, esculturas y fondo de archivo entre otros.

\section{Estado de conservación de los fondos}

La misma heterogeneidad que presentan los fondos en tipología se ve reflejada en la heterogeneidad del estado de conservación que presentan las 
piezas, dependiendo de los materiales que las componen, del uso que se le dio a las mismas o de la forma de almacenaje en la que se encontraba.

Generalmente, el estado en el que se encuentran la mayoría de las piezas se rige por el uso que se les dio a las mismas, puesto que se trata de piezas que precisaban de ser tocadas, manipuladas, guardarlas, volver a usarlas, puesto que tenían una finalidad pedagógica.

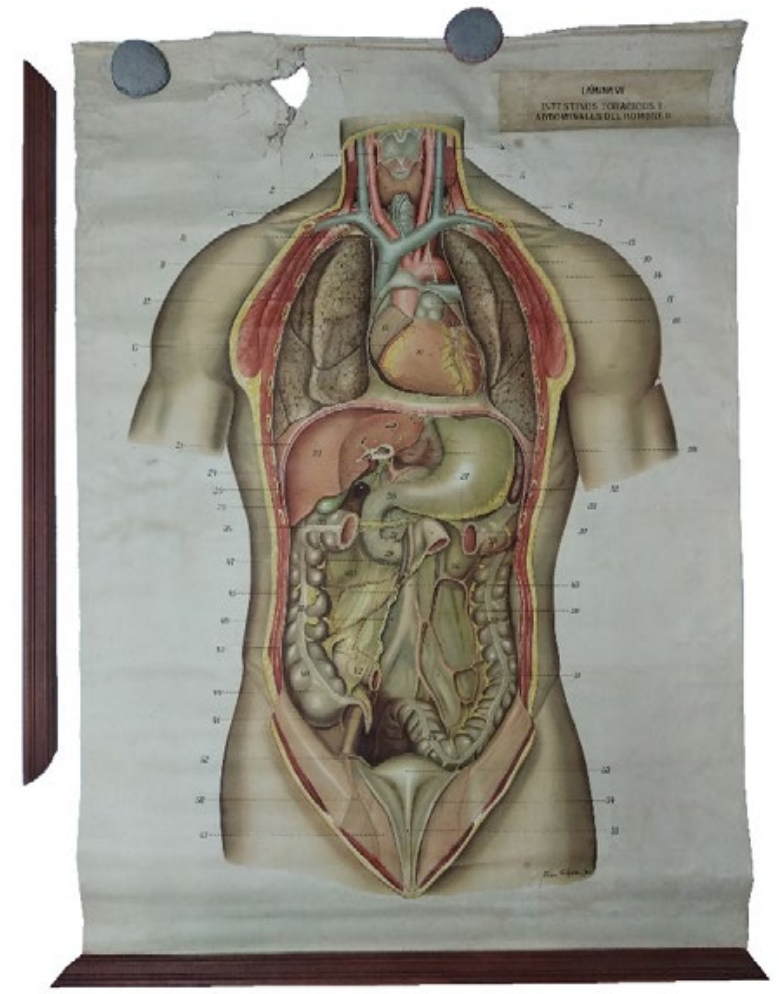

Figura 1. Lámina VII, intestinos torácicos y abdominales del hombre II. Antes de la intervención. 


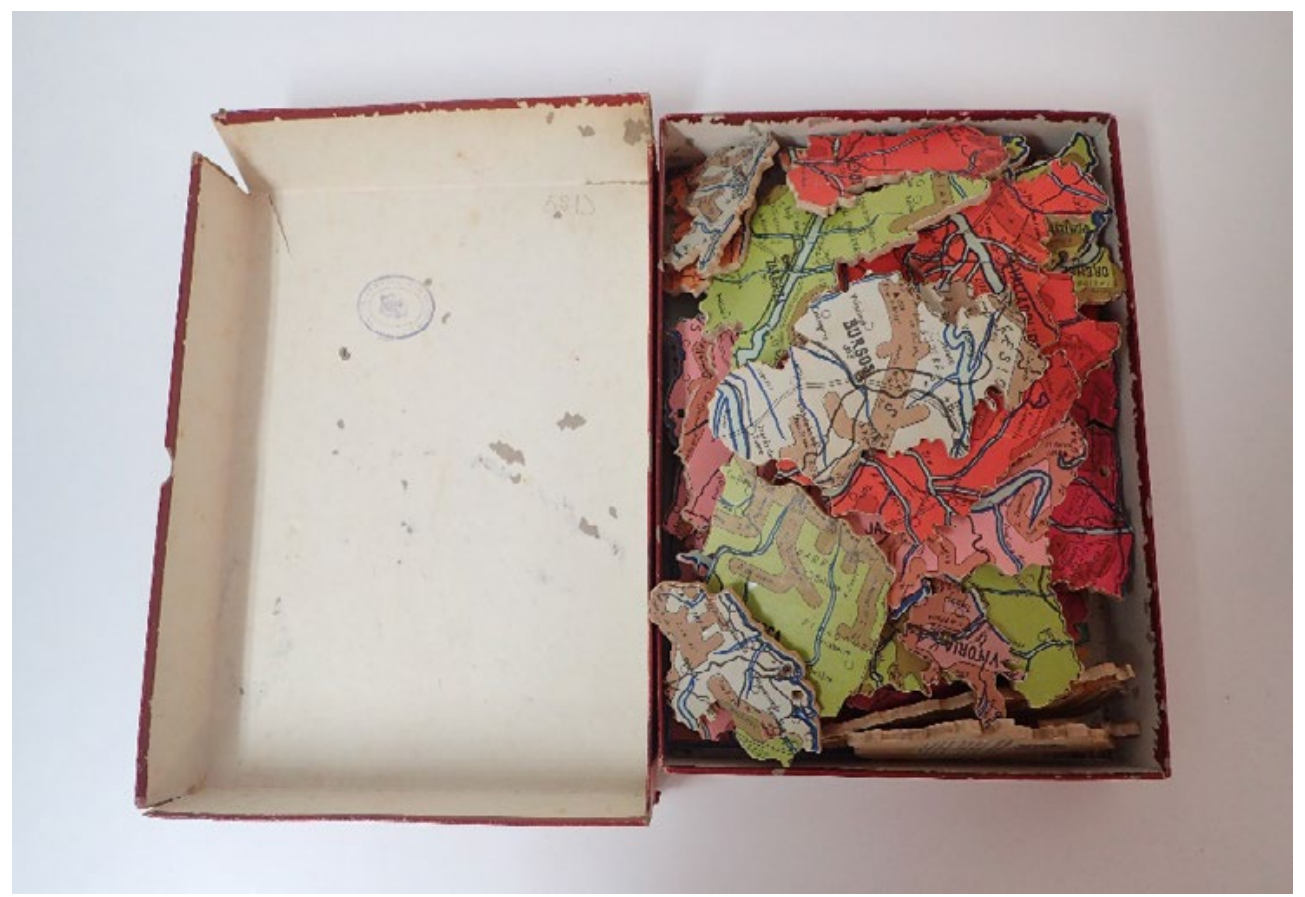

Figura 2. Puzle de las provincias de España en su caja original. Antes de la intervención.

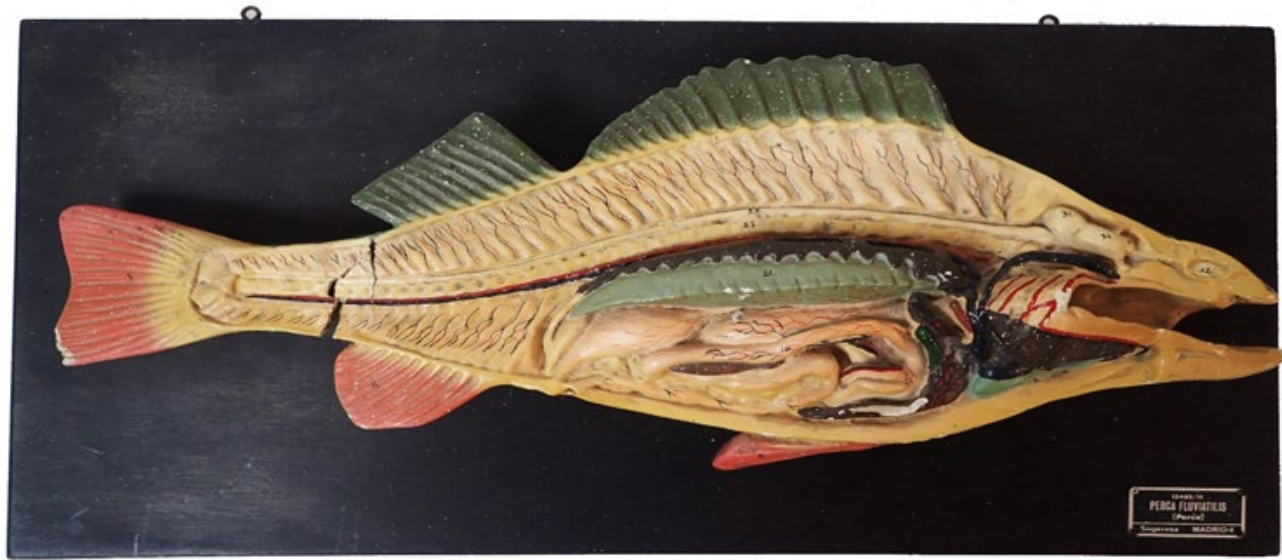

Figura 3. Maqueta de perca. Antes de la intervención. 


\section{Intervenciones realizadas según el estado de conservación}

Tal y como se describe, una de las principales misiones del museo es conservar este fondo para su estudio y difusión y restaurar aquellos objetos que están en peligro de perder su integridad física, estética o histórica. Por este motivo, el museo se ha preocupado de tener sus fondos en constante recuperación, restaurando los objetos que necesitan ser intervenidos y estableciendo nuevos parámetros de conservación, formas de almacenamiento y catalogación. Dada la gran cantidad de objetos que forman la colección, el criterio dependerá del estado de conservación de las piezas, como de la propuesta de exposición e itinerancia de estas, situación que se ha dado en estos últimos meses. En este artículo se abarcan las diferentes intervenciones que han sido realizadas hasta el momento y los motivos por los cuales se han priorizado ciertas piezas a otras.

Algunos de los objetos restaurados hasta la fecha son un modelo anatómico desmontable destinado a la enseñanza del cuerpo humano, mapas físicos y políticos escolares de papel, una serie de mapas negros pintados a mano que permiten ser escritos con tiza, modelos botánicos, modelos geográficos, maquetas de animales, un puzle y cajas de almacenaje individualizadas de conservación para las obras más frágiles. Generalmente, todos estos objetos presentan un estado de conservación de acuerdo con la naturaleza de sus materiales y almacenamiento. Los daños más representativos han sido ocasionados por el uso que se les ha dado a las piezas para la enseñanza y en los años que han sido almacenadas, puesto que el problema principal de conservación de estos objetos es que, desde su creación, han sido concebidos para el uso y no para la exposición y la contemplación. 

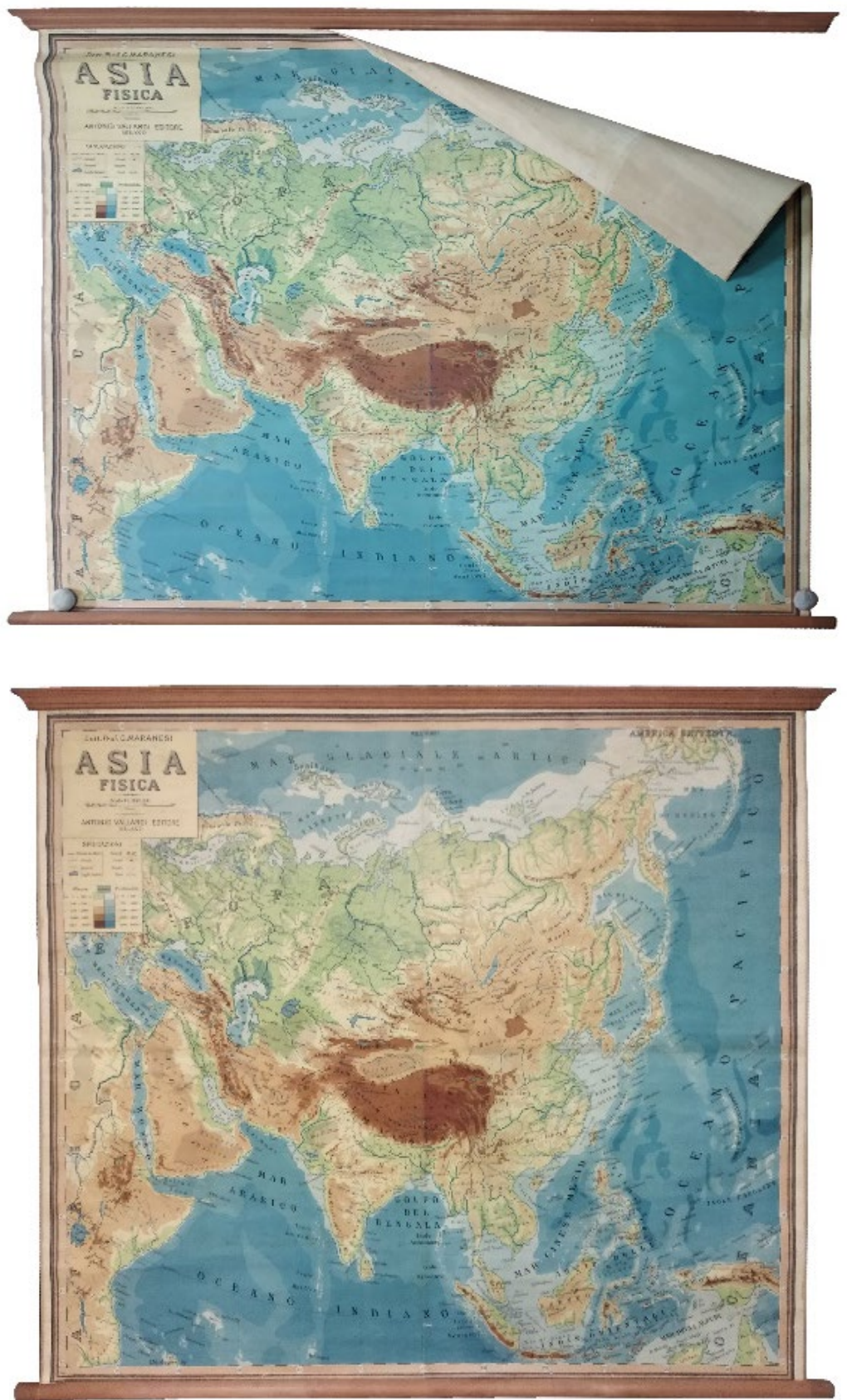

Figura 4. Mapa físico de Asia. Antes y después.

Los mapas escolares y láminas (ejemplo en figuras 4 y 5) restaurados son, en su mayoría exceptuando algún caso, de papel entelado y clavados a dos listones de madera que permitían su manipulación y ser colgados para 
su estudio. El estado de conservación de estos era diverso. Generalmente, presentaban suciedad superficial (polvo, huevos de insectos, etc.), roturas del papel, pérdida de adhesión del papel respecto al empañado y desclavado los listones debido a la rotura del papel y la tela en contacto con los clavos.

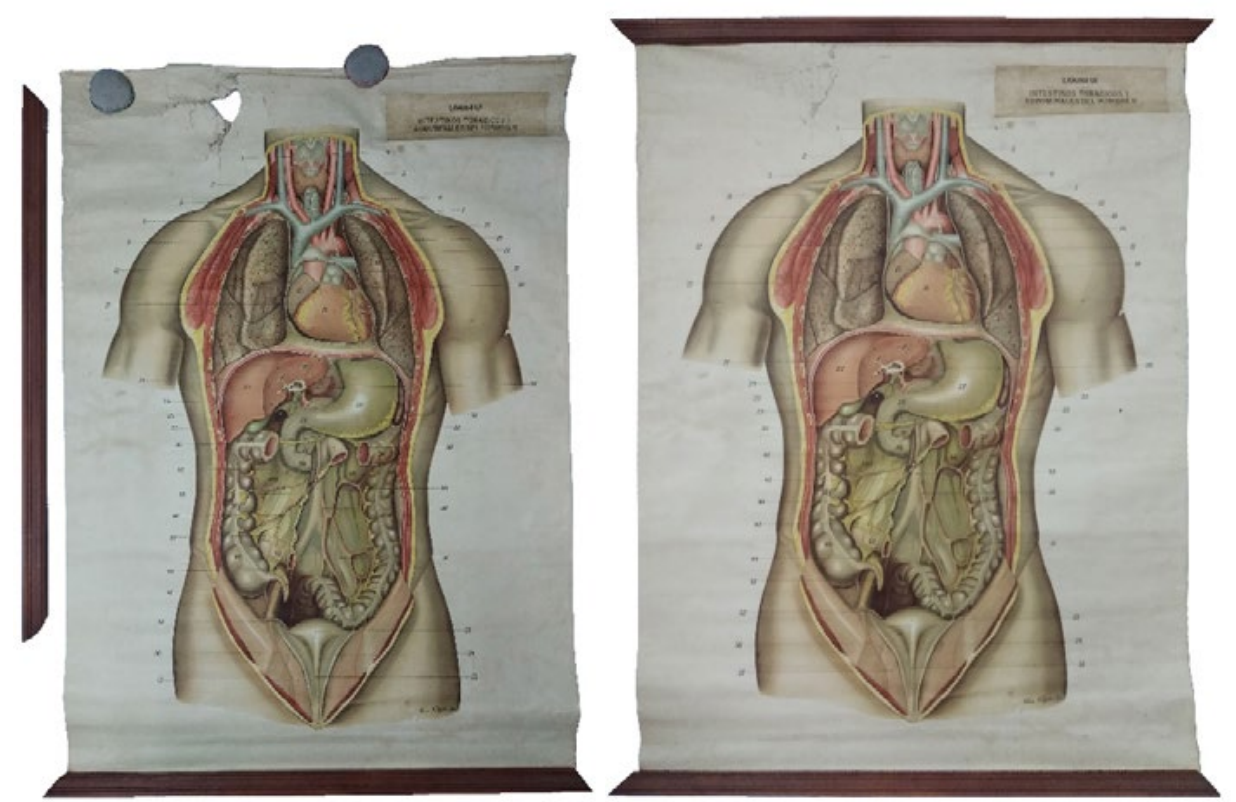

Figura 5. Lámina VII, intestinos torácicos y abdominales del hombre II. Antes y después.

Por otra parte, los mapas negros (figura 6) presentaban patologías diferentes, ya que están hechos de materiales diferentes a los anteriores. Estos están compuestos por dos listones de madera que sujetan mediante claves una tela de arpillera o saco impregnada de un material negro tipo brea, a su vez pintado a mano. Este tipo de brea, al tratarse de un material con temperatura de transición vítrea baja, se encuentra ligeramente mordiente a temperatura ambiente. Esto ha generado que, como los mapas se encontraban almacenados unos sobre otros, se hayan quedado embebidos en este material trozos e hilos de la tela de arpillera de la trasera del resto. Las tareas principales de restauración han sido la limpieza superficial de los mapas y la propuesta de conservación preventiva adecuada para este tipo de obras. 


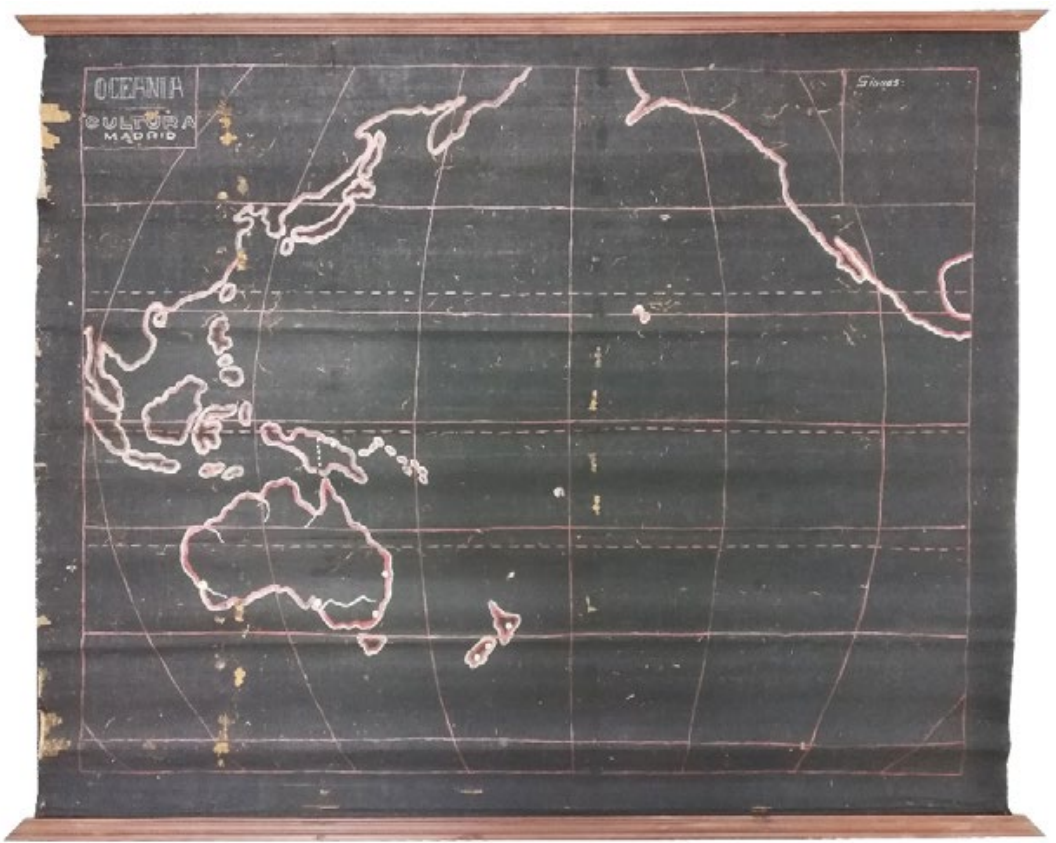

Figura 6. Mapa negro de Oceanía. Antes y después.

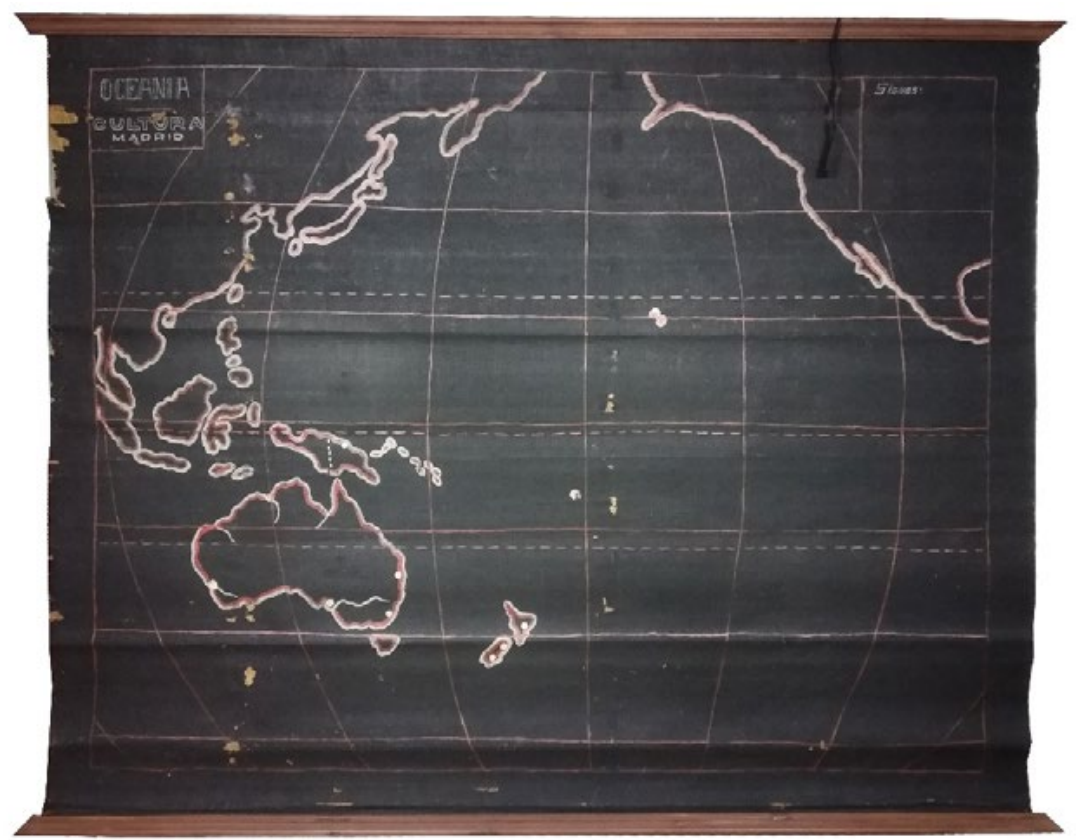

El caso del modelo anatómico desmontable (figura 7) es muy diferente. Al tratarse de un objeto tridimensional, presenta otro tipo de problemas. En este caso, el modelo presentaba gran cantidad de suciedad superficial, restos de cinta adhesiva y golpes, puesto que hasta el momento había sufrido un almacenamiento deficiente, lo que provocó en una ocasión su caída. Esta caída 
frontal contra el suelo tuvo como consecuencia su rotura por los tobillos, tórax y rostro. Dada la naturaleza de la obra y su función, la restauración de esta escultura abarcó principalmente el montaje y recuperación de las partes rotas y perdidas para que pudiera volver a estar de pie en posición vertical sobre su pedestal, soportándose por sí misma.

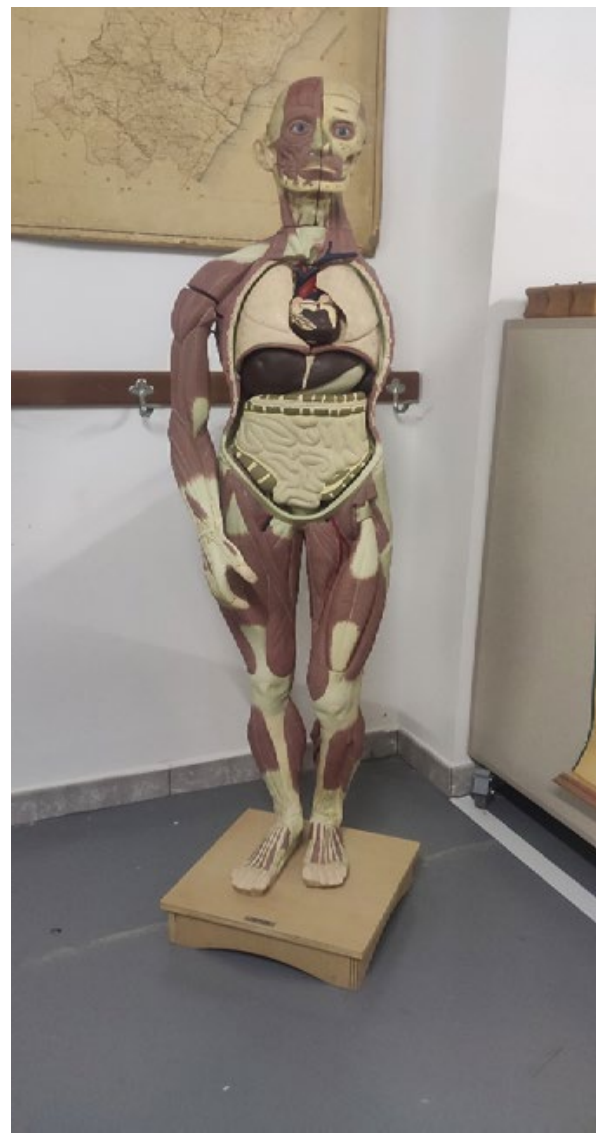

Figura 7. Modelo anatómico desmontable. Antes y después.

En cuanto a las maquetas o modelos de tipo geográfico (figura 8), botánico o de animales, se puede afirmar de forma general que todos presentaban suciedad superficial ocasionada por la acumulación de polvo ambiental. Los daños físicos se descubrieron eran a causa del uso que implicaba su desmontaje y posterior montaje y los métodos de almacenamiento utilizados hasta el momento. Los tratamientos realizados en estas piezas comenzaron por una limpieza mecánica de la suciedad superficial seguida de una limpieza 
química (figura 9). Por último, se reintegraron volumétricamente y cromáticamente dichos faltantes (figura 10).

Todos los tratamientos de conservación y restauración realizados cumplen con los principios de conservación y restauración, como la mínima intervención y la reversibilidad y discernibilidad los tratamientos y materiales añadidos. Las intervenciones han sido realizadas siempre desde el punto de vista de la conservación de los objetos a largo plazo, tanto y almacenes como en exposiciones, ya que muchas son prestadas temporalmente a otras entidades para su exposición museística.

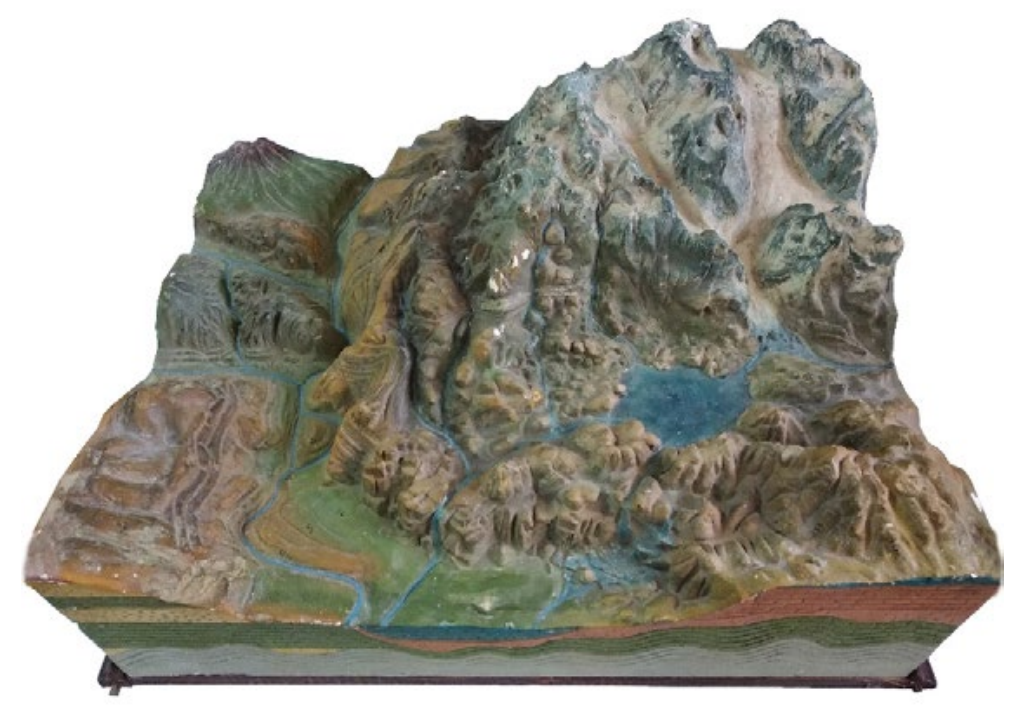

Figura 8. Modelo geográfico. Antes y después.

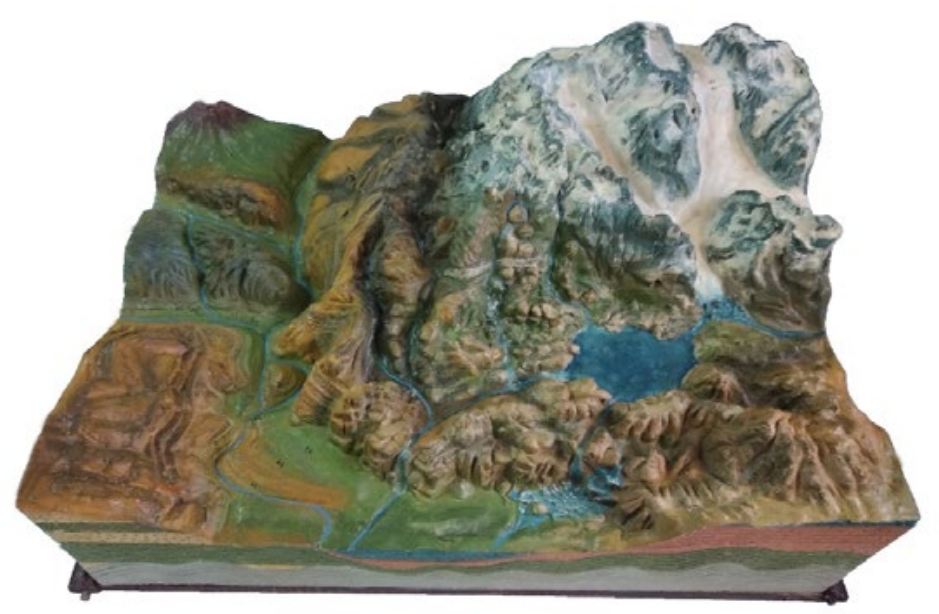




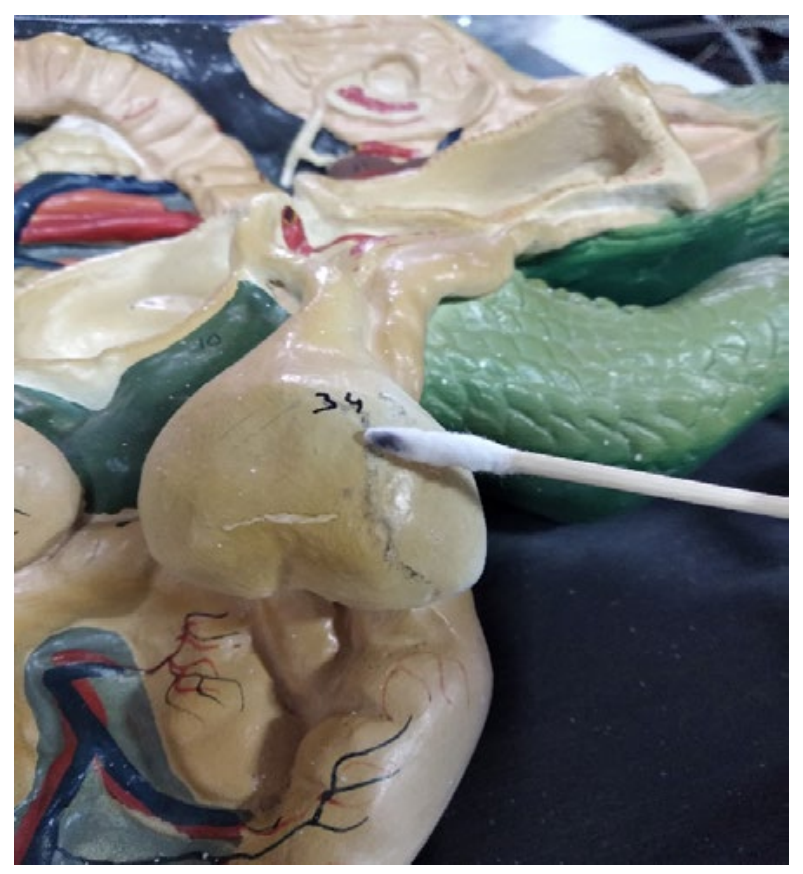

Figura 9. Limpieza química de la suciedad superficial de una maqueta de animal.

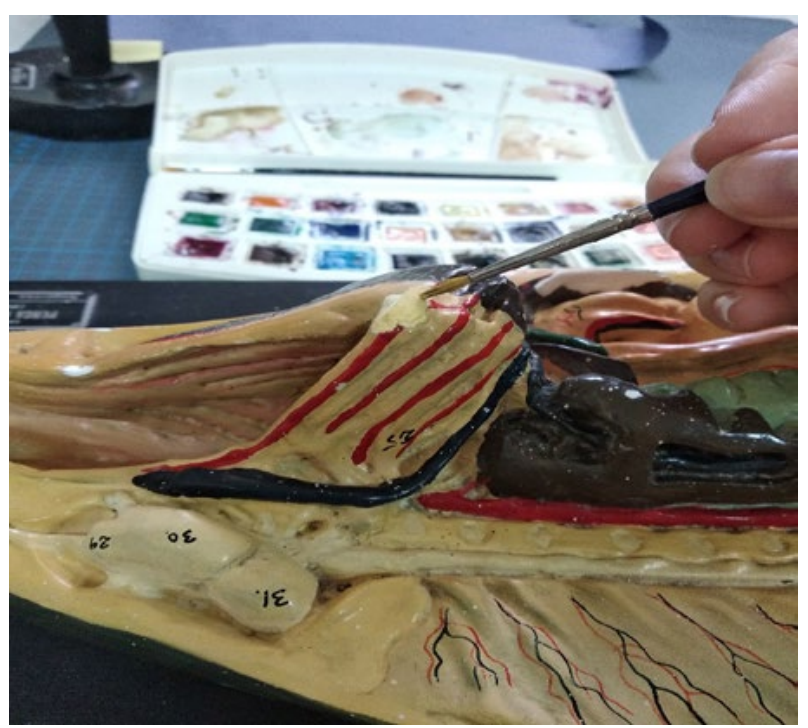

Figura 10. Reintegración cromática de un faltante reintegrado volumétricamente de una maqueta de animal. 


\section{Conclusiones}

De acuerdo con el ICOM (Consejo Internacional de Museos), el museo "es una institución sin fines lucrativos, permanente, al servicio de la sociedad y de su desarrollo, abierta al público, que adquiere, conserva, investiga, comunica y expone el patrimonio material e inmaterial de la humanidad y su medio ambiente con fines de educación, estudio y recreo" (ICOM, 2007). El MPdC es una institución con estructura formal que vela por cubrir las funciones básicas de un museo: investigación, conservación del patrimonio, educación, difusión y, finalmente, exposición. Prueba de ello son las intervenciones anteriormente explicadas, así como las numerosas exposiciones que organizan y las cesiones temporales de obras a otras entidades. Se trata pues de una institución en auge que trabaja por y para los ciudadanos.

- Se trata de una colección de piezas muy variadas procedentes de diferentes disciplinas de la educación, siendo pues un fondo cuya heterogeneidad lo hace rico y único, a la vez que complejo en labores generales de conservación.

- Debido a la complejidad de intervención algunas piezas por falta de antecedentes conocidos en el campo de la conservación, se está sentando precedente en algunas de las intervenciones directas de los objetos. Un ejemplo del caso anterior son los modelos anatómicos desmontables. Lo más habitual es encontrarlos realizados en cera (Del Moral Azanza, 2016) (Sánchez Ortiz, 2015) o papel maché (Martín Villa y Piñar Gallardo, 2013) y no de yeso hueco colado como los modelos anatómicos del fondo del MPdC (existen referencias bibliográficas a esculturas de yeso y escayola para la enseñanza de dibujo y pintura en facultades de Bellas Artes, pero no son la misma tipología de objeto que nos ocupa) (Gasca Miramón, 2019) (Grafiá Sales et al., 2011 y 2012). Este hecho hace que estas piezas sean peculiares y le aporten valor a la colección.

- Por el contrario, sí que existen referencias bibliográficas sobre la conservación y restauración de cartografía didáctica que ayudaron a establecer los criterios de actuación para este tipo de piezas del fondo del MPdC (Martínez Sánchez, 2016) (Ziaurriz, 2017). 
- A medida que se van ampliando los trabajos en materia de conservación y restauración, se van descubriendo nuevas necesidades y se van realizando mejoras que van aportándole más valor al conjunto. Por tanto, puede afirmarse que se trata de un museo vivo implicado con sus labores por y para el patrimonio.

\section{Bibliografía y referencias}

ACRE, El Código Ético del Conservador-Restaurador (Confederación Europea de Organizaciones de Conservadores-Restauradores, 2003, disponible en: [https://asociacion-acre.org/el-conservador-restaurador/codigo-etico-del-conservador-restaurador/]).

Fermina Valeria Ziaurriz, Proceso de estabilización de obra plana entelada de gran formato: Toma de decisiones, gestión de recursos y técnicas aplicadas (Buenos Aires: Presentación, IV Encuentro nacional de instituciones con fondos antiguos y raros, Biblioteca Nacional Mariano Moreno, 2017).

ICOM, Definición de Museo [Estatutos del ICOM, 2007, disponible en: [https://icom.museum/es/recursos/normas-y-directrices/definicion-del-museo/]).

Isabel Martínez Sánchez, La restauración y salvaguarda de cartografía didáctica de gran formato (Pátina, nº 19, 2016), 125-141.

José Vicente Grafiá Sales, José Manuel Simón Cortés, M ${ }^{\mathrm{a}}$ Victoria Vivancos Ramón, Carmen Duréndez Hernández y Ma Ángeles Máñez Cardo, Proceso de intervención en la restauración de los modelos académicos de la Facultad de Bellas Artes (Valncia: Arché, Publicación del Instituto Universitario de Restauración del Patrimonio de la Universitat Politècnica de Valencia, $n^{\circ} 6$ y 7, 2011 y 2012), 151-156.

Judit María Gasca Miramón, Conservación y restauración de esculturas en yeso en la Real Academia de Bellas Artes de San Fernando (Madrid: Universidad Complutense de Madrid, Facultad de Bellas Artes, Departamento de Pintura, Escultura, 2019).

María Alicia Sánchez Ortiz, Restauración de modelos anatómicos en cera: Colección del Real Colegio de Cirugía de San Carlos (Ge-conservación, $n^{\circ}$ 7, 2015), 37-49. 
Nerea del Moral Azanza, Cirugía restauradora: restauración estructural de modelos anatómicos en cera. (Madrid: Universidad Complutense de Madrid, Facultad de Bellas Artes, Departamento de Pintura, Pintura y Restauración, 2016).

Rafael Martín Villa e Isabel Piñar Gallardo, Investigación y restauración de modelos didácticos del gabinete de historia natural del IES San Isidro (Burgos: VII Jornadas de Institutos Históricos de España, 2013). 